\title{
Bony Union and Flap Resorption in Cranioplasty with Autologous Subcutaneous Pocket Preserved Bone Flap: Early Report on an Ambidirectional CT Scan-Based Study
}

\author{
Sudip Kumar Sengupta ${ }^{1}$ Andrews Navin Kumar ${ }^{2}$ Vinay Maurya ${ }^{3}$ Harish Bajaj ${ }^{4}$ \\ Krishan Kumar Yadav ${ }^{4, \odot}$ Ashwath K.G. ${ }^{4}$ Dharamjeet Singh Faujdar ${ }^{5}$ \\ ${ }^{1}$ Department of Neurosurgery, Command Hospital (Southern \\ Command), Pune, Maharashtra, India \\ 2Department of Maxillofacial Surgery, Command Medical Dental \\ Centre (Eastern Command), Kolkata, West Bengal, India \\ ${ }^{3}$ Department of Radiodiagnosis, Base Hospital Delhi Cantonment, \\ New Delhi, India \\ ${ }^{4}$ Department of Neurosurgery, Command Hospital (Eastern \\ Command), Kolkata, West Bengal, India \\ ${ }^{5}$ Department of Social and Preventive Medicine, AFMC, Pune, \\ Maharashtra, India \\ Indian J Neurosurg 2021;1:26-36. \\ Address for correspondence Sudip Kumar Sengupta, MS, MCh, \\ Department of Neurosurgery, Command Hospital (Southern \\ Command), Pune 411040, Maharashtra, India \\ (e-mail: sudipdebashree@gmail.com).
}

\begin{abstract}
Keywords

- cranioplasty

- autologous bone

- bony union

- aseptic resorption

Introduction Absence of sufficient number of prospective randomized controlled studies and comparatively small sample size and short follow-up period of most of the studies, available so far, have left ambiguity and lack of standardization of different aspects of cranioplasty.

Materials and Methods This is an early report of a computed tomography scan image-based ambidirectional study on cranioplasties performed with autologous subcutaneous pocket preserved bone flaps. Retrospective arm compared bony union and factors influencing it between cranioplasties and craniotomies. Patients with poor bony union and aseptic resorption were followed up in the prospective arm.

Results Retrospective arm of the study, followed up for five years (mean 32.2 months), comprised 42 patients as cases (Group 1) and 29 as controls (Group 2). Twentyseven individuals (64.3\%) in Group 1 had good bony union, as compared with $20(68.9 \%)$ good unions in Group 2 out of the 29 patients. Four patients (9.5\%) in Group 1 showed evidence of flap resorption, a finding absent in any patient in Group 2. Age, sex, smoking habits, superficial skin infection, and method of fixation did not appear to have any implication on bony union. Craniotomies done using Gigli saws fared better as compared with those done with pneumatic saw with lesser flap size-craniectomy size discrepancy, though it was not statistically significant. Fifteen patients have been included in the Prospective arm at the time of submission of this article.

Conclusion Ours is a study with a small sample size, unable to put its weight on any side, but can surely add some more data to help the Neurosurgeons in choosing the best for their patients.
\end{abstract}

DOI https://doi.org/ 10.1055/s-0040-1714317 ISSN 2277-954X.
(C2021. Neurological Surgeons' Society of India.

This is an open access article published by Thieme under the terms of the Creative Commons Attribution-NonDerivative-NonCommercial-License, permitting copying and reproduction so long as the original work is given appropriate credit. Contents may not be used for commercial purposes, or adapted, remixed, transformed or built upon. (https://creativecommons.org/licenses/by-nc-nd/4.0/).

Thieme Medical and Scientific Publishers Pvt. Ltd. A-12, 2nd Floor, Sector 2, Noida-201301 UP, India 


\section{Introduction}

Decompressive craniectomy (DC) is a useful tool to counter refractory raised intracranial pressure (ICP) of varied etiology with varied success rates reported by different authors. ${ }^{1-7}$ Use of this technique in the setting of traumatic brain injury is on the rise. ${ }^{8}$ DC is to be followed up by a second surgery, cranioplasty, once the crisis of raised ICP has been managed successfully. Different materials have been recommended to be used to achieve the bone cover, with each having their own advantages, documented by the proponents. ${ }^{9-13}$ Autologous bone continues to be the most commonly used material for cranioplasty, whenever available, and still considered the gold standard. ${ }^{14}$ For the interval between the craniotomy and cranioplasty, the bone flap requires preservation. Several techniques have been used for the bone flap preservation among which preservation in subcutaneous pocket and cryopreservation are the most commonly used methods. ${ }^{15-17}$ Even the cryopreservation techniques are not standardized. ${ }^{18}$ Both DC and cranioplasty are in vogue for more than 5,000 years. ${ }^{19,20}$ However, there still remain unsettled controversies regarding each aspect of the surgery. One of the most important reasons for this confusion is the inability to conduct a prospective randomized controlled study to compare different techniques due to ethical issues, and comparatively small sample size and short follow-up period of most of the studies available so far. It can be safely said that unlike the long bones where the issues of bony union and nonunion have been extensively investigated and settled, our knowledge of calvarial bones is yet rudimentary and our understanding is based more on clinical experience than evidence. We conducted this ambidirectional study with an intention to study the various factors affecting the union of free bone flap or its resorption, after cranioplasty with subcutaneous pocket preserved autologous bone flap, with cases of craniotomy, where free bone flaps were replaced primarily, serving as the controls. This is an early report of a study that is ongoing with an aim to continue for three more years.

\section{Materials and Methods}

\section{Study Design}

This is an early report of an ongoing computed tomography (CT) scan image-based ambidirectional case control study conducted at our center, being reported on completion of the retrospective arm. In the retrospective arm of the study, the autologous subcutaneous abdominal pocket preserved cranioplasty cases were included in Group 1 and were compared with Group 2 consisting of the patients who underwent craniotomies where bone flaps were replaced primarily, forming the controls. Patients detected to have evidence of poor bone union were prospectively followed up to look for evidence of progression of bony union on one hand and flap resorption on the other and the factors associated with each.

\section{Data Collection: Retrospective Arm}

In November 2016, medical records of all the patients who underwent cranioplasty at our center in previous 5 years were obtained. The indication, patient particulars, and operative techniques for craniotomy and cranioplasty were noted down from the operative notes. The patients or their caregivers were contacted telephonically to ask about their well-being and inquired if they had undergone a CT scan of the head at any center postoperatively. From the archives of the concerned radiology center, images were retrieved on a compact disc (CD). Patients who were asymptomatic and never underwent a postoperative CT scan, or whose neuroimagings of the postoperative period were not archived by the radiology center, were requested to participate in the study after duly explaining the risk associated with radiation exposure and obtaining their consent. All the patients who undergo craniotomy are routinely requested to report for follow-up annually at our Neurosurgery outpatient department. Those from faraway places prefer a review by general surgeons or neurosurgeons in their localities and only come back to us on specific indications. However, these outstation patients were followed up telephonically and their CT scan images, if available, were collected on CDs.

\section{Data Collection: Prospective Arm}

Patients who had features of poor bony union were requested to undergo a follow-up CT scan of the head in view of possibility of a flap resorption. Those who complied constituted the prospective arm of our study.

\section{Data Analysis}

The data were loaded on Philips Brilliance 16 slice CT scan machine at our center and analyzed with Statistical Package for the Social Sciences (IBM, Armonk, New York, United States) software version 26 . The different parameters were measured independently by a radiologist, a neurosurgeon, and a maxillofacial surgeon. An average of the three was entered in the study.

\section{Parameters Measured}

Age, sex, and smoking habits of the individual, comorbidities and indication for surgery; and presence or absence of hydrocephalus were noted from hospital records. Craniectomy size and shape were recorded from the CT scan images. The operative technique, tool used for craniotomy, additional nibbling of the cranium done at the craniotomy margins were recorded from the archived operative notes. Techniques used for bone fixation were grouped as rigid fixation, suture fixation, and no fixation from operative notes. The maximum and minimum recordable gaps between the bone flap and the craniotomy margin were recorded from the CT scan images in the nonunited parts of the defect. Intervals between the primary surgery and cranioplasty and between the cranioplasty and neuroimaging were noted from the hospital records.

\section{Exclusion Criteria}

Patients less than 20 years of age and any patient with history of radiation exposure in the postoperative period were excluded from the study. 


\section{Cranioplasty Interval Classification}

1. Ultra-early: $<3$ weeks

2. Early: $3-12$ weeks

3. Late: $12-24$ weeks

4. Delayed: $>24$ weeks

\section{Measurement of Various Parameters}

The fixed reference points used for measuring various parameters were selected before the actual measurements were taken up, by the principal author, either on the bone flap or at fixed bony points on the cranium ( - Fig. 1A). Each measurement was then taken thrice by each of the three investigators: a radiologist, a neurosurgeon, and a maxillofacial surgeon. An average of the nine readings was tabulated.

\section{Measuring Extent of Union}

Circumference of the craniotomy margin was measured on the CT scan volumetric reconstruction image along with the length of the segment showing evidence of bony union ( - Fig. 1B). The union was classified into three groups: $>50 \%$, $25-50 \%$, and $<25 \%$. Last group was considered to have a poor bony union and were planned to be followed up in the prospective arm of the study.

\section{Parameters for Bone Resorption}

Connecting two fixed reference points, straight lines were drawn. Length of the bone flap and craniectomy defect were measured on these lines on volume reconstruction three-dimensional images ( $\boldsymbol{\sim}$ Fig. 1C, D). On axial CT scan images, radiologically evident gap between the craniectomy edge and the edge of the cranioplasty flap was measured at various points and the smallest measurement was recorded ( -Fig. 1E). Any site where a titanium screw, applied during cranioplasty, was noted to have lost its bony anchorage was considered to be an evidence of bone resorption ( - Fig. 2E, F). We did not resort to bone mineral density studies.

\section{Statistical Analysis}

Statistical analysis was done using a software STATA version 14

\section{Results}

A total of 71 patients were included in the study, 42 as cases (Group 1) and 29 as controls (Group 2). The mean duration of follow-up for the patients in the retrospective arm for cases was 32.2 months (minimum 18 months, maximum 64 months). The mean duration of follow-up for the patients in the retrospective arm for controls was 21.5 months (minimum 8 months, maximum 108 months). The mean duration of follow-up for the patients in the prospective arm was 11 months (minimum 8 months, maximum 14 months).

There was no significant difference in symptomatology of the cases and controls with majority reporting for ipsilateral $(63 \%)$ or ill-defined (22\%) headache, and vertigo (26\%). However, irritability/forgetfulness was commoner among

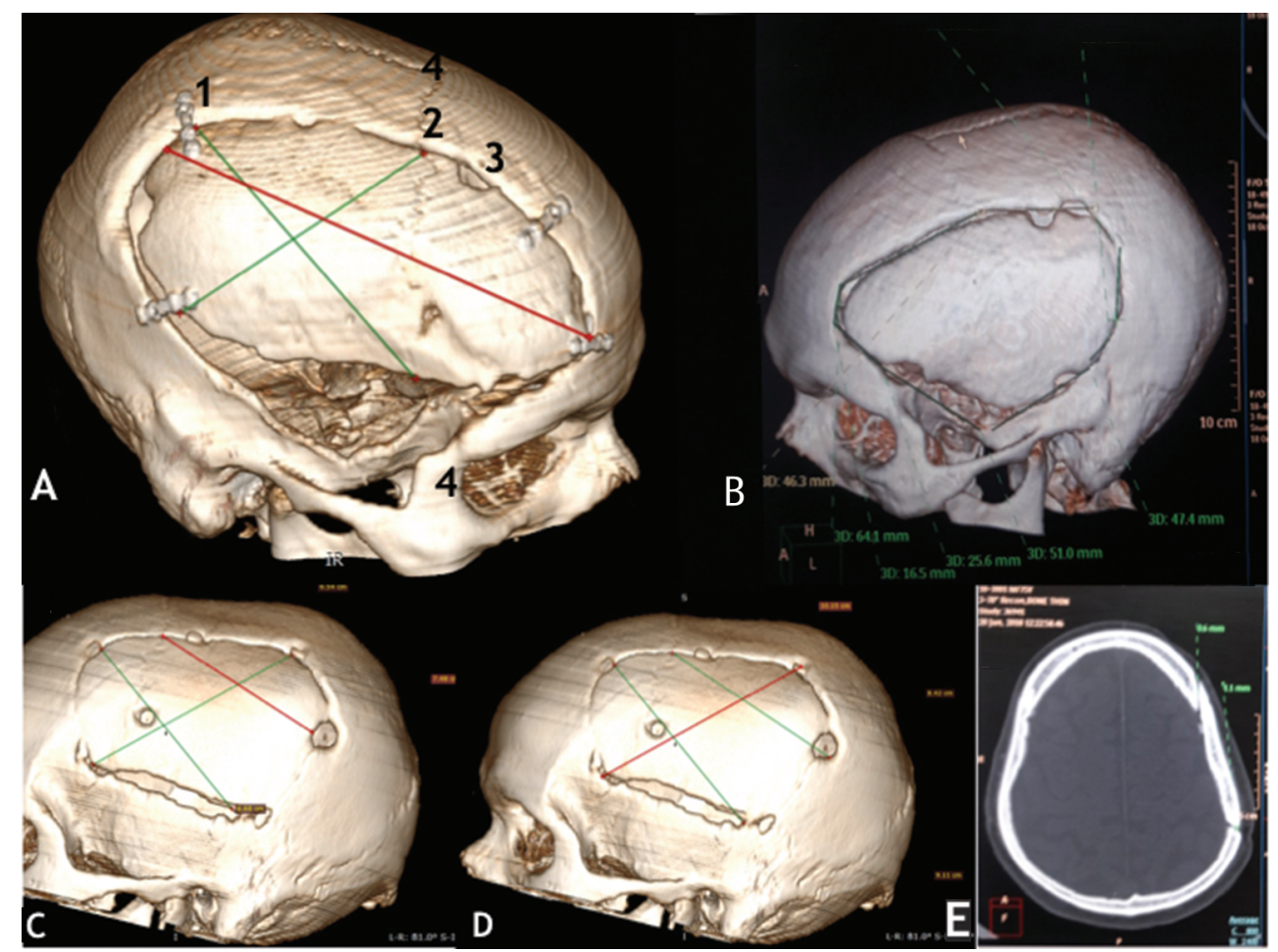

Fig. 1 Measurement protocols: (A) Fixed points were selected on the bone flap [titanium screw (1), intersection of the margin of the flap with a suture line (2), and midpoint of a burr hole (3)] or a fixed bony landmarks on the cranium (4). Connecting these points, straight lines were drawn. (C, D) Size of the bone flap (C) and craniectomy defect (D) were measured on these lines. (B) On volumetric reconstruction three-dimensional images, length of the segments where there was bony union (measurements by convention were placed in the top half of the screen) and segments without bony union (measurements by convention were placed in the bottom half of the screen) were measured. (E) On axial section, gaps between the craniotomy edge and edge of the bone flap were measured at various sections and smallest distance was recorded. 


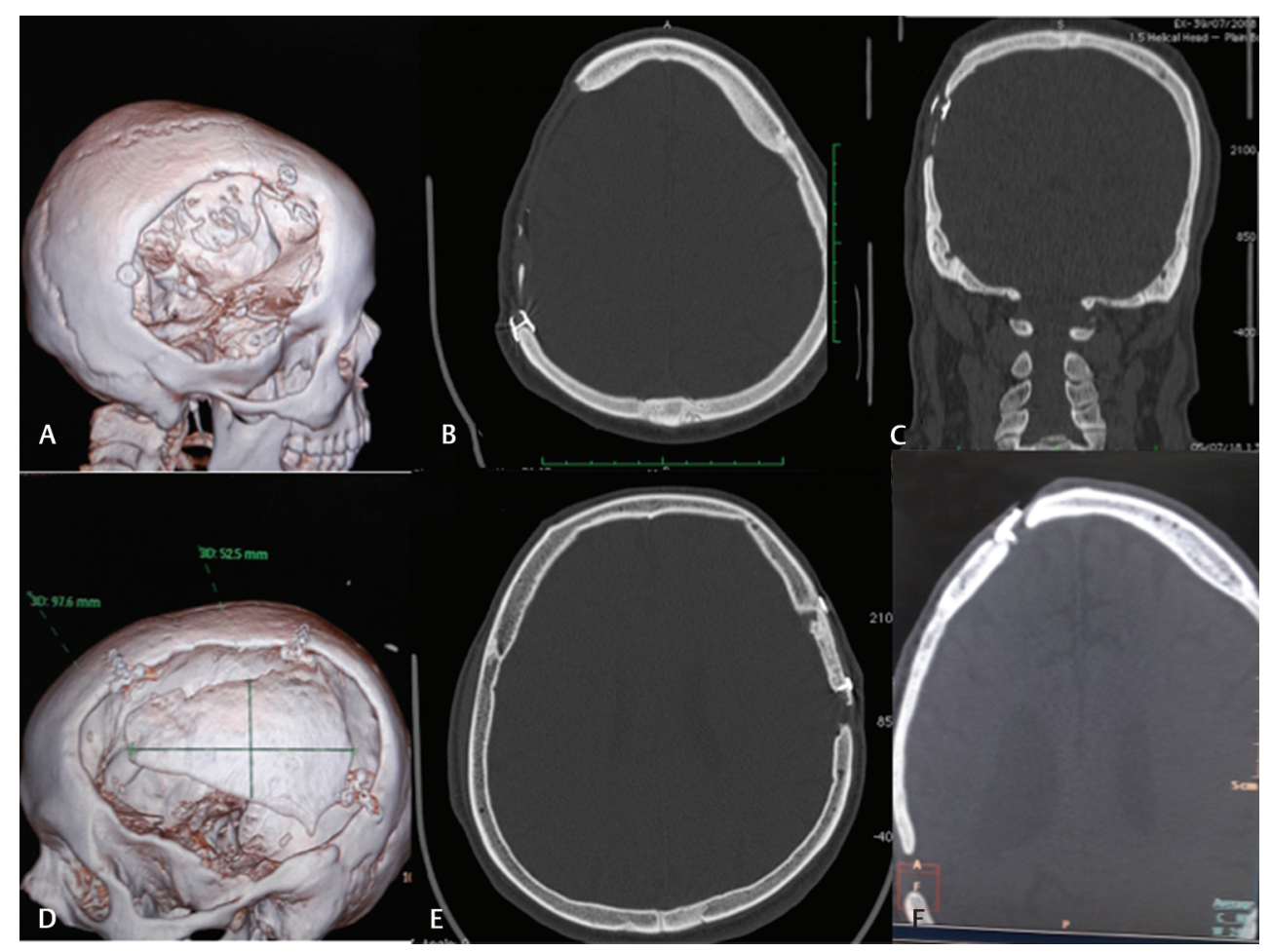

Fig. 2 Aseptic bone resorption. (A-C) Volumetric reconstruction and axial section showing moth-eaten appearance of the resorbed bone flap. (D) Circumferential bone flap resorption. (E, F) Evidence of bone flap resorption in view of the loss of bony anchorage of the titanium plates and screws used for fixation. In all the images, the cranial contour appears preserved.

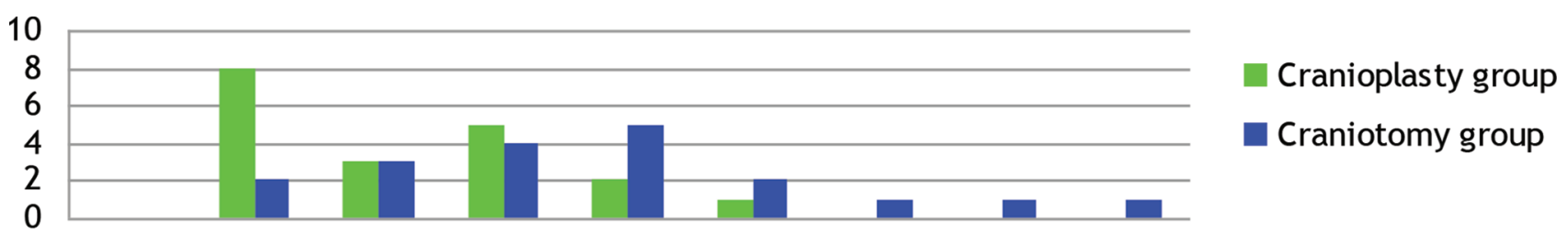

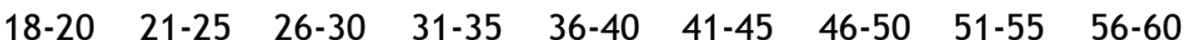

Fig. 3 Age at the time of surgery. Age groups in " $X$ " axis plotted against number of patients in each group in " $Y$ " axis.

patients with history of head injury (16\%) than those without it $(6 \%)$. Three patients in Group 1, including one who turned out to have an absorbed bone flap, were asymptomatic.

\section{Epidemiology}

Forty-two patients with a mean age of 36.83 years and standard deviation (SD) of 2.5 (range 20-76 years) were included as cases (Group 1) in the retrospective arm of our study. Twenty-nine patients who underwent craniotomy for various indications formed the control group (Group 2) of the retrospective arm, with a mean age of 41.4 years and SD of 2.8 ( - Fig. 3). Among cases, 37 were males and 5 females, while in the control group there were 20 males and 9 females.

\section{Analysis}

Retrospective Arm

Out of the 55 patients who had undergone cranioplasty at our center, 39 patients had undergone a CT scan examination due to various symptoms that were considered related to the cranial surgery by the treating physician. Three asymptomatic patients consented to participate in the study and underwent noncontrast $\mathrm{CT}$ head at our center. Six patients could not be contacted on telephone or through postal communication. Two patients had expired due to unrelated disease conditions in the years following cranioplasty. Three asymptomatic patients declined to undergo any neuroimaging. In two patients, the CT scan image could not be retrieved from the radiology center. There were nine smokers each in both the groups. Twenty-seven individuals (64.3\%) in Group 1 had good bony union while 15 failed to have a good union, as compared with 20 (68.9\%) good unions in Group 2 out of the 29 patients. Four patients (9.5\%) in Group 1 showed evidence of flap resorption (-Fig. 2), a finding absent in any patient in Group 2.

The factors influencing the extent of good bony union (union involving $>50 \%$ of craniotomy margin) are as under:

1. Craniotomy tool: Gigli saw was used to perform craniotomy in 23 cases and pneumatic drill in 19 cases. Among the controls, Gigli saw was used in 8 cases and pneumatic 
drill in 16 cases while in 5 cases of comminuted depressed fracture, bone fragments were elevated along the fracture lines after an initial adjacent mini-craniectomy. Four out of the five patients with skull fracture showed good bony union while the fifth patient with significant bone loss had poor union. Following cranioplasty (Group 1), those whose craniotomy was done with a Gigli saw were found to have a better rate and extent of bony union (69.6\%) as compared with those in whom craniotomy was done with a pneumatic saw (57.9\%; odds ratio [OR]: 1.7 ; $95 \%$ confidence interval $[\mathrm{CI}]: 0.46-5.9)$, but this difference was statistically not significant $(p=0.43$ ). Better union rate after use of Gigli saw was also seen among the controls (Group 2; 87.2\%) as compared with the pneumatic saw (56.3\%; OR: 5.4; 95\% CI: 0.54-55.2); however, this was also not statically significant $(p=0.15)$. Both Groups 1 and 2 combined, Gigli saw use (-Fig. 4) was associated with a better rate of union (OR: 1.9; 95\% CI: $0.7-5.3$ ), but again the superiority was statistically not significant $(p=0.2)$.

2. Method of bone fixation: In Group 1, bone flaps were either rigidly fixed (27 cases) with titanium miniplates and screws or were fixed with Prolene sutures (15 cases). Rigid fixation was also done with titanium clamps. In Group 2, there were three different methods applied while putting the bone flap back. They were rigidly fixed with titanium miniplates and screws in nine patients and suture fixed in six patients. Bone flaps were replaced and left loosely over the craniectomy defect without any fixation in 14 craniotomy patients. In both the groups, outcome was similar when bone flaps were secured by rigid fixation or suture fixation technique, which fared better in terms of bone union as compared with unfixed bones (OR: 1.23; 95\% CI: 0.39-3.9), though the difference was statistically not significant $(p=0.7)$. In five patients $(35.7 \%)$ among those cases of craniotomy where bone flaps were not fixed, there was no bony union at all ( - Fig. 5).

3. Effect of smoking on bony union: Among all smokers ( $n=18$ ) in the study (both cases and controls), 38.9\% failed to achieve a good bony union (OR: $0.74 ; 95 \% \mathrm{CI}: 0.2-2.2$ ), but it was not found to be statistically significant $(p=0.6)$. In a sub-analysis among cases $(n=42), 55.6 \%$ of smokers $(n=9)$ had poor union (OR: 0.35 ; 95\% CI: 0.07-1.6), while among controls $(n=29), 22.2 \%$ of smokers $(n=9)$ had poor union (OR: $1.9 ; 95 \% \mathrm{CI}: 0.3-11.6)$, but in both cases and controls, it was not statistically significant $(p=0.17$ and $p=0.5$, respectively).

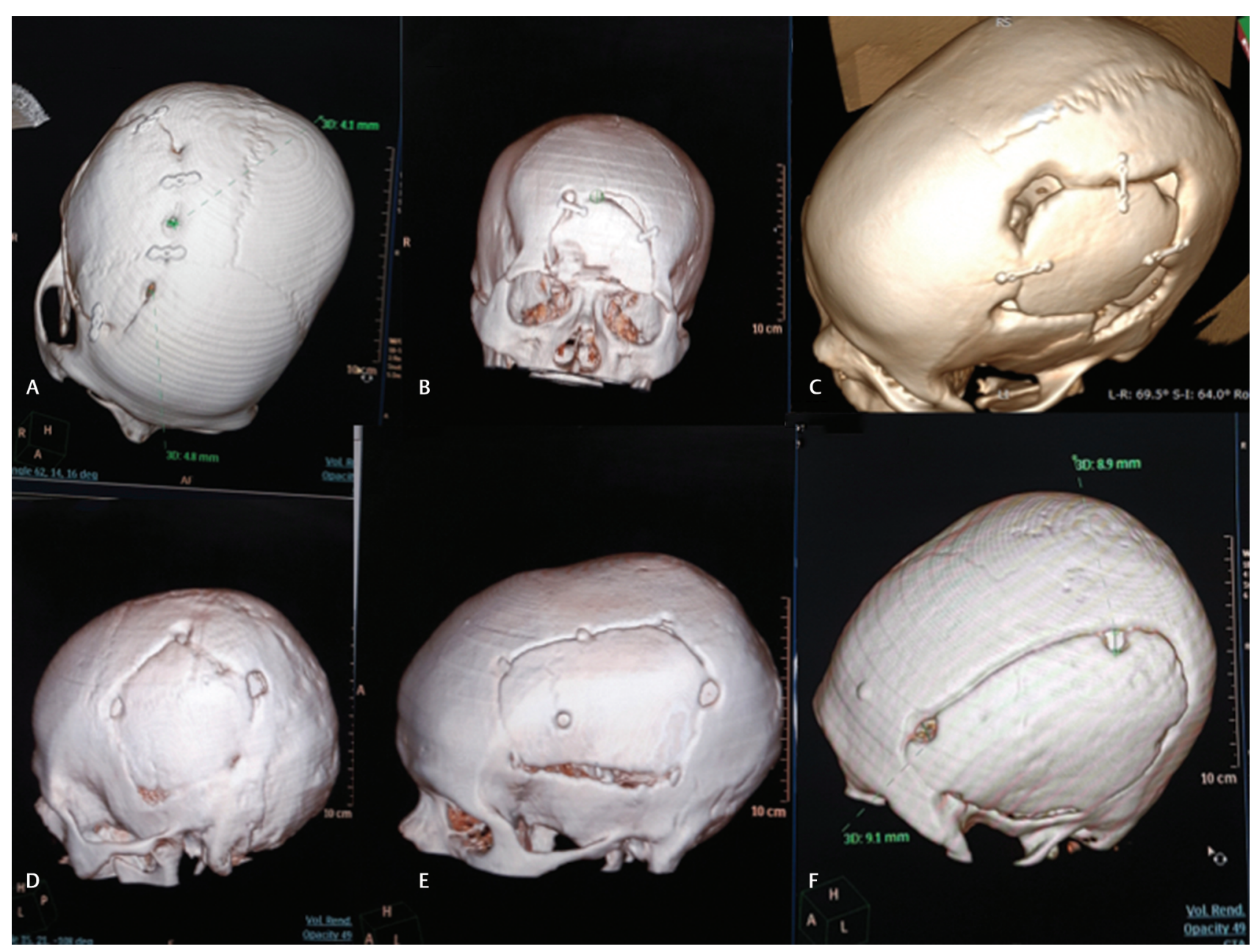

Fig. 4 Craniotomies performed with Gigli saw had marginally better rate of bony union with (A-C) or without (D-F) any fixation of bone flap. 


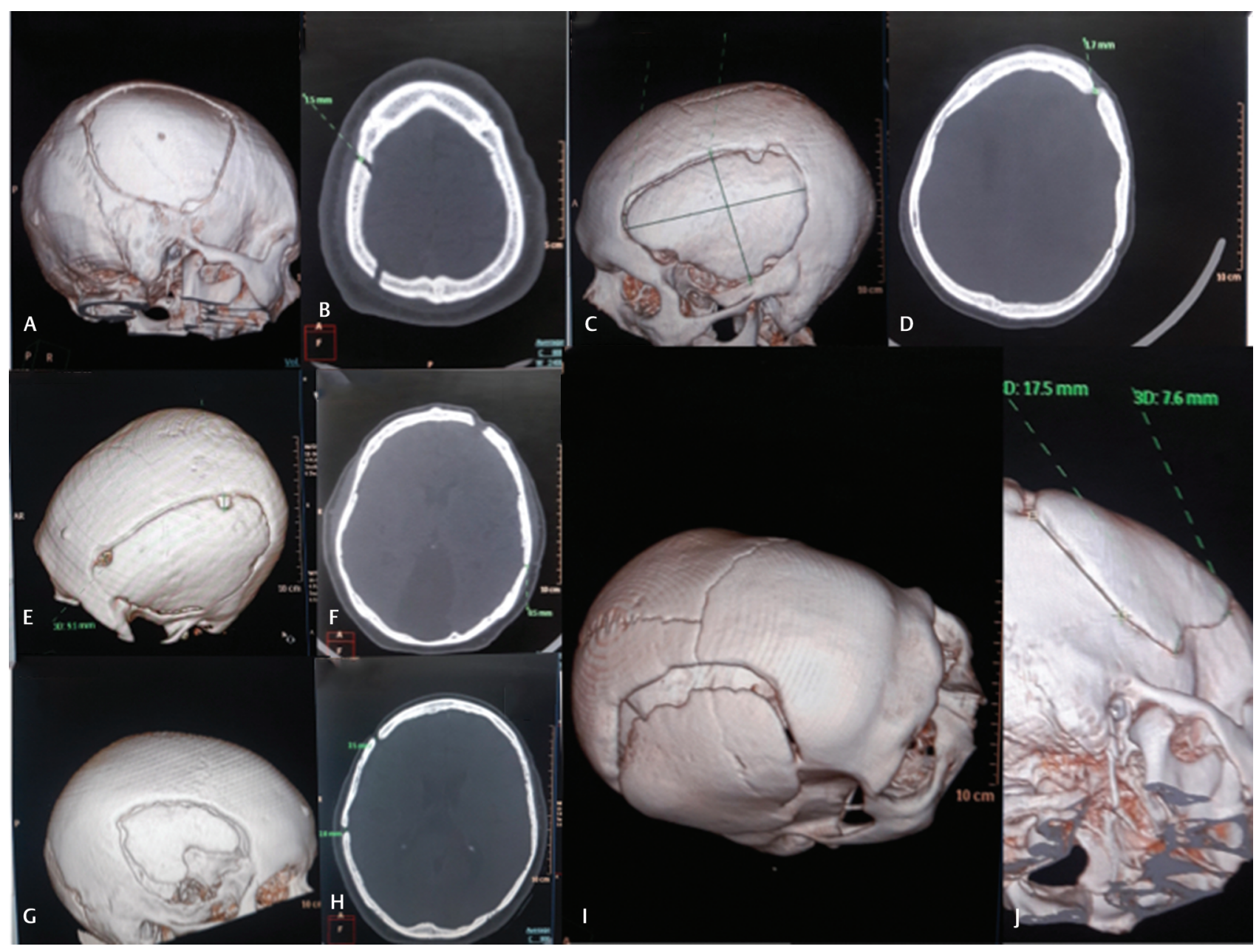

Fig. 5 Cases of nonunion of unsecured bone flaps: Following craniotomies in the control group (Group 2), when bone flaps were left unsecured over the craniectomy defect. (A, C, E, G) Volumetric reconstruction images. (B, D, F, H) Images showing axial computed tomography scan sections with measurements of the craniectomy margin-bone flap edge interval at sections where the measurements were found to be minimum for respective cases. (I, J) Unsecured bone flap found to have migrated caudally increasing the craniectomy margin-bone flap edge interval at the medial side leading to nonunion, while on the lateral side of the flap, there was good bony union.

4. Infection: Eight patients (six cases and two controls) had superficial skin infections, all of whom went on to have a good bony union. One case with abscess formation, who was managed with parenteral antibiotics and daily dressings, went on to have flap resorption.

5. Age: There was no statistically significant change in rate of good union with increasing age in both cases and controls.

6. Timing of cranioplasty: On analyzing the cases (- Table 1) for good union among ultra-early, early, late, and delayed groups, good union was found to be significantly lower $(p<0.05)$ in early group (35.7\% cases), while in late group (12 weeks to 6 months) good union was found to be significantly higher $(83.3 \%$ cases, $p<0.05)$.

7. Hydrocephalus: One patient each from case and control cohorts had hydrocephalus, which developed after cranioplasty requiring cerebrospinal fluid diversion. Both had good ( $>50 \%$ circumference) bony union ( - Fig. 6 )

8. Flap resorption: Of the two patients with significant flap resorptions, one was asymptomatic and the second had ill-defined headache on exertion, a symptom common among the rest of the patients in the cranioplasty group. None had any feature of sunken flap syndrome.
Table 1 Correlation : Cranioplasty interval and Good bony union

\begin{tabular}{|l|l|l|l|}
\hline Cases $(n=42)$ & $\begin{array}{l}\text { Good bony } \\
\text { union }\end{array}$ & $\begin{array}{l}\text { Bivariate OR } \\
(95 \% \text { CI) }\end{array}$ & $p$-Value \\
\hline Ultra-early $(n=3)$ & $2(66.6 \%)$ & $1.1(0.09-13.4)$ & 0.9 \\
\hline Early $(n=14)$ & $5(35.7 \%)$ & $0.15(0.03-0.62)$ & 0.009 \\
\hline Late $(n=18)$ & $15(83.3 \%)$ & $5(1.1-21.8)$ & 0.03 \\
\hline Delayed $(n=7)$ & $5(71.4 \%)$ & $1.4(0.24-8.73)$ & 0.6 \\
\hline
\end{tabular}

Abbreviation: $\mathrm{OR}$, odds ratio; $\mathrm{Cl}$, confidence interval.

9. Craniectomy-bone flap size discrepancy was less in craniotomies done using Gigli saw as compared with those performed using the pneumatic saw, and was also more in the delayed cranioplasty group as compared with the ultra-early and early groups. And the difference was statistically significant $(p<0.05)$.

\section{Prospective Arm}

Out of the 25 patients (16 cases and 9 controls) who failed to achieve a good radiological bony union and were eligible for inclusion in the prospective arm of the study, 8 were 


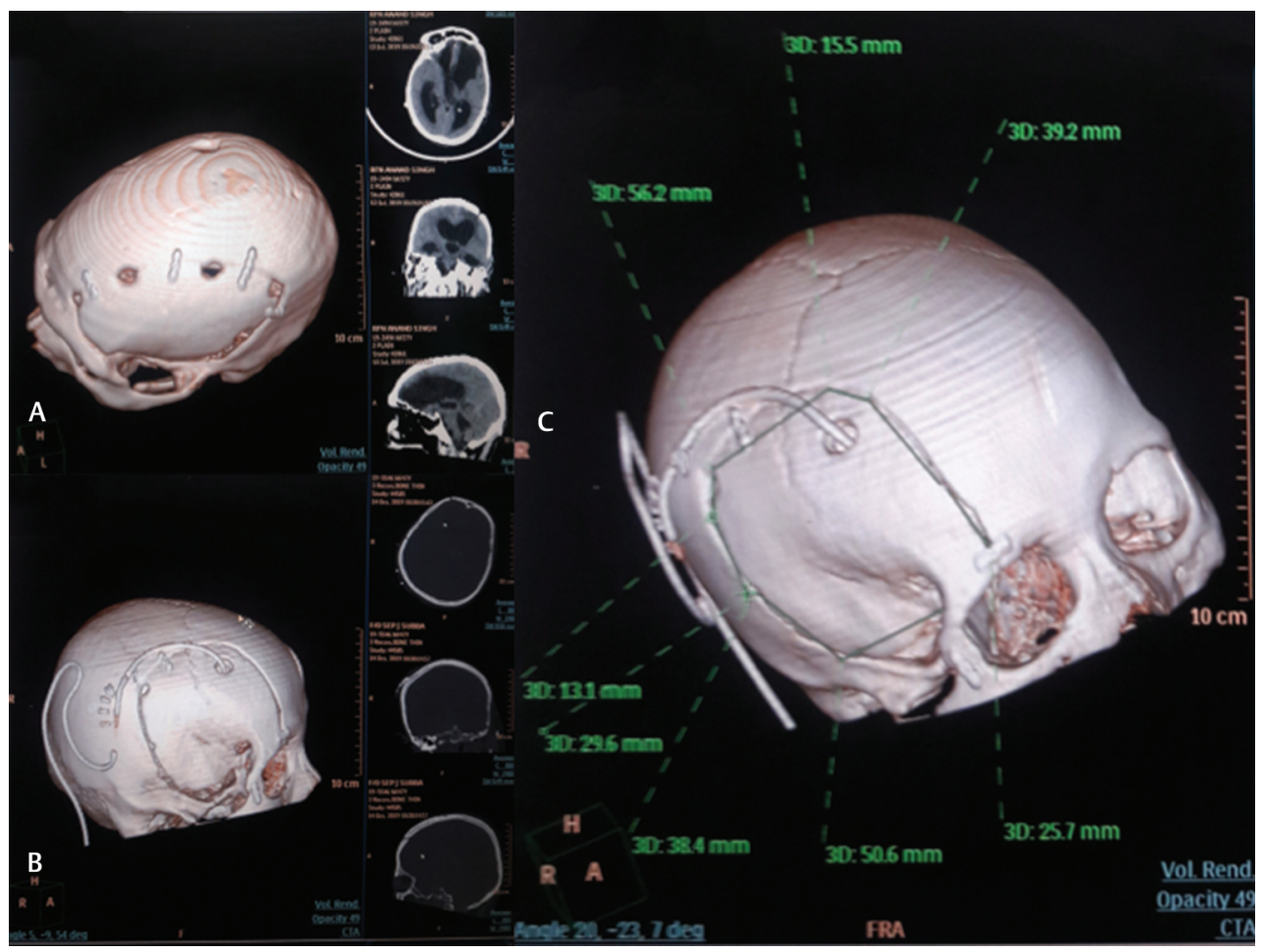

Fig. 6 Bony union in presence of hydrocephalus. (A) Cranioplasty done between 3 and 6 months. (B) A case of third ventricular mass with hydrocephalus (operated) required a ventriculoperitoneal shunt 3 years after initial craniotomy. (C) Areas of radiological bony union measurements shown on the upper half of the image and nonunited segments in the lower half.

asymptomatic. Out of these asymptomatic patients, six declined to undergo any repeat CT scan, and this included one patient with aseptic flap absorption ( - Fig. 2A-C). Two patients, one on immune surveillance and another with coronary artery disease, expired before completion of 1 year of follow-up. One patient, who had agreed for a repeat CT scan after 1 year, could not be traced subsequently, either telephonically or by postal correspondence. In one patient who got a repeat CT scan at a peripheral center, images could not be retrieved. Fifteen of the remaining patients were included in the prospective arm and their CT scan images were analyzed. Recruitment and follow-up in this arm are ongoing and planned to be continued for next 3 years with change in the principal authors, as and when they get posted out from the institute. The parameters analyzed and the findings are as under:

1. On repeating $\mathrm{CT}$ scans after 1 year, the flaps were found to have reduced in size in all directions ( - Fig. 7A-E).

2. Bony union appeared to be ongoing even after an interval of 3 years; however, while all bone gaps less than $0.4 \mathrm{~mm}$ appeared to have progressed to healing in scans repeated after 1 year, none with more than $1.5 \mathrm{~mm}$ showed any progression toward healing.

3. No burr hole in any of the patients appeared to have closed even after a follow-up of more than 7 years.

4. Out of the 14 patients in whom bone flaws were left loosely over the craniectomy defect in view of, or anticipating, any brain swelling, 5 did not unite. In four of them, the gap between the craniotomy edge and edge of the bone flap was more than $5 \mathrm{~mm}(-$ Fig. $4 \mathrm{~A}-\mathrm{H})$ and the gap did not reduce on follow-up scans. One bone flap had migrated caudally creating large inter-edge gap except at the temporal part, where it had healed ( - Figs. $4 \mathbf{I}$ and $\mathbf{J}$ ).

\section{Discussion}

For a surgical technique, which is in use for more than 5,000 years, cranioplasty still continues to have too many unresolved issues concerning nearly every aspect of the surgery, for example, timing, material to be used, fixation technique, and even follow-up requirements. ${ }^{20}$ However, its utility is universally accepted and so is the necessity to know more about it. ${ }^{21}$ Most of the studies conducted are retrospective in nature ${ }^{18,22}$ and ethical issues have kept prospective randomized studies to a very small count. ${ }^{23}$ Its low cost, absence of any concern for rejection, satisfactory rate of bony union, and logistical ease for the patient and hospital makes subcutaneous pocket preserved autologous bone flap a frequently used material in many countries including ours. ${ }^{24-}$ ${ }^{27}$ However, some other authors have found cryopreserved bone flaps to be more convenient to give better results and have exclusively used cryopreservation for bone flaps at their centers. There are as many protagonists of cryopreservation of the flap ${ }^{28,29}$ as there are distractors. ${ }^{30,31}$ There is, however, a voice growing louder by the day recommending artificial materials to be superior to both. ${ }^{23,32}$ In our institute, cryopreservation of bone flap is not practiced. We discard the bone flaps only in moribund patients or those with bleeding 


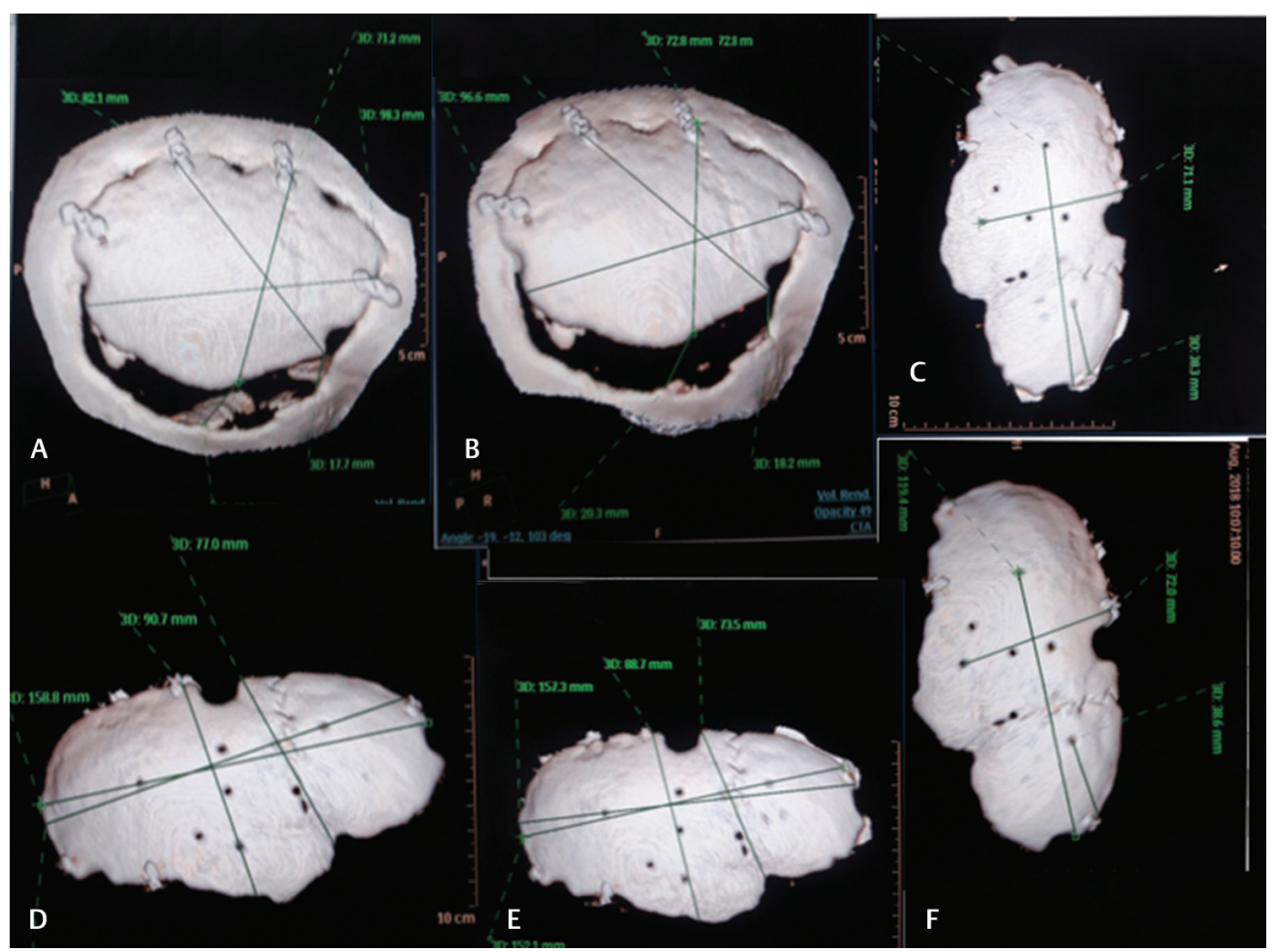

Fig. 7 Measurements of the bone flap on serial computed tomography scans in the prospective arm revealed reduction in the size of the flaps. (A, C, E) Images obtained in 2018. (B, D, F) The follow-up images after an interval of 1 year. C-F belong to the same patient.

diathesis. We resort to cranioplasty using artificial materials only when there is no bone flap available for cranioplasty, a situation that arises when either the bone flap has not been preserved or has been discarded due to infection or when there is extensive flap resorption.

The concluded retrograde arm of the ambidirectional study at our center had 42 cases of cranioplasty as against 25 other craniotomies performed for various indications, serving as controls. The two groups matched well in age distribution. The mean age of the patients in Group 1 was 36.83 years with majority of our cases in 21-35 years age group, which was similar to the study (mean 33.44 years in cases and 41.4 years in controls) by Andrabi et $\mathrm{a}^{21}$ and Shoakazemi et $\mathrm{a}^{27}$ but was younger as compared with the study (49.6 years) by Adaaquah et al. ${ }^{33} \mathrm{~A}$ predominance of young males among the cases is commensurate with the known male preponderance in patients suffering from traumatic brain injury as well as a greater likelihood of a young patient surviving a traumatic brain injury to undergo cranioplasty. ${ }^{34}$ In our study, we did not find any correlation between the age and sex of the individual in both the cases and controls, to achieving good bony union. This finding was similar to the study published by Adaaquah et al. ${ }^{22}$ The bony union involving more than $50 \%$ of craniectomy circumference, considered "good union" in our study, was achieved in $64.2 \%$ of cases following cranioplasty as compared with $68.9 \%$ of controls comprising of patients undergoing craniotomy. Jeon et al, ${ }^{35}$ after comparing 276 craniotomies and 93 cranioplasties with cryopreserved bone flaps, found bone fusion rates of $76.6 \%$ in the craniotomy group and $53.3 \%$ in the cranioplasty group at 6 months postsurgery $(p=0.015)$ and $78.6 \%$ and $78.1 \%$, respectively, at 1 year post surgery. Since, in our study, the mean follow-up of both the cohorts were more than 2 years, the finding that fusion rate in both the cohorts are similar after 1 year is echoed in both the studies.

Till not very long back, the usual recommendation was to delay cranioplasty by at least 6 months, from the primary surgery, to avoid complications. The delay advocated was even more for penetrating injuries. ${ }^{36}$ The concept has since drifted gradually to support a cranioplasty as early as the subsidence of the brain swelling permits the procedure. In the retrospective study by Andrabi et al, ${ }^{21}$ out of the 236 patients only 6 had a subcutaneous pocket preserved autologous bone flap, while 190 were cryopreserved. Complications were most commonly seen in patients $(18.29 \%$, $n=15)$ who had undergone cranioplasty after 6 months of the initial primary procedure $(p=0.520)$. Reoperation rate of $10.98 \%$ was seen in patients undergoing cranioplasty greater than 24 weeks from the primary procedure $(p=0.316)$. In their retrospective study, Bjornson et al compared early cranioplasty (33-90 days interval) with late cranioplasty (more than 90 days interval) and found no statistical difference between the two in complication rates. ${ }^{37}$ In a retrospective study on 108 cases of cranioplasty by Ernst et $\mathrm{al}^{31}$ in which subcutaneous bone flap storage was done, the mean time to cranioplasty was 104.31 days. However, they did not study the correlation between the bony union and the interval between the primary surgery and cranioplasty. By the beginning of the twenty-first century, it became acceptable to do cranioplasty between 3 and 6 months, ${ }^{38}$ as the advantages of 
early restoration of Monro-Kellie doctrine started to become clearer. Carvi et al $^{39}$ reported on cranioplasties done within 3 weeks of craniotomy. Voices started to grow further negating advantages in delaying cranioplasty. ${ }^{40} \mathrm{~A}$ review article published in 2011 comparing 18 articles concluded that there was no significant difference in rate of complications between cranioplasty performed within 3 months of craniectomy and cranioplasty after 3 months. ${ }^{18}$ Another concept that has yet to be settled is how to define and group the cranioplasty intervals. Early and late cranioplasties are the two common terminologies used and defined, respectively, as a cranioplasty done before or after 3 months of the index surgery. ${ }^{18,40}$ There are studies where all the cranioplasties have been grouped together for studying the outcome, irrespective of the time interval between the DC and cranioplasty. ${ }^{41}$ We have added two more categories to the popular early and late groups, namely (i) ultra-early, where cranioplasty is done within 3 weeks, during the same hospital admission period, and (ii) delayed, when due to a specific reason, for example, wound infection, cranioplasty has been delayed beyond 6 months. This was done because we felt that, first, these two groups have different outcomes in respect to neurological recovery and bony union and, second, the ultra-early cranioplasty requires recognition and wider acceptability in clinical practice. In our study, we found the best bony union rate in cranioplasties done between 12 weeks and 6 months with an odds of good union in this group five times higher than poor union $(p<0.05)$ and the worst bony union rate among cranioplasties done between 3 and 12 weeks (bony union rate of 35.7\%). Ultra-early cranioplasties performed before 3 weeks during the same hospital admission period fared in between the two (bony union rate of $66.6 \%$ ).

For securing the bone flap with the cranium, suturing was used previously; use of miniplates and screws is the norm in most of the centers as on date..$^{23,27,36} \mathrm{We}$, at our center, use miniplates and screws, and titanium clamps and Prolene sutures alternatively to secure bone flap. In the control group, we had five patients in whom bone flaps were loosely left over the craniectomy defect without fixation. Though fixation in some form resulted in a better rate of good union than no fixation at all, in terms of bony union ( $O R=1.23$; but $p=0.7$ ), there was no significant difference between different fixations by titanium miniplates and suturing. This was in variance to what Karl-Dieter Lerch suggested following his cadaveric study showing titanium clamp to be superior to titanium miniplates and both significantly better than suturing. ${ }^{42}$ In the retrospective study by Adaaquah et al, ${ }^{33}$ 171 patients of craniotomy were reported upon for bony union after a follow-up of 6-74 months with CT scan. In their study, $94 \%$ had rigid fixation with plates, and $6 \%$ had sutures or wire fixation and reported a strong statistical trend toward bony union in patients who received plates compared with those who had sutures ( $p=0.0585$ ).

At our center, the follow-up imaging of choice is magnetic resonance imaging scan. CT scans are done only if there is a suspicion of a hydrocephalus or chronic subdural hematoma. The patients being followed up in peripheral centers often underwent CT scans, being a cheaper and widely available investigation modality. All the CT scan raw data were collected on CDs. In some peripheral neuroimaging centers, images are not archived and are deleted from the hard disc after 3 months or when the drive is full. The time intervals of CT scans from the date of surgery were hence nonhomogeneous in our study.

Aseptic bone resorption has been frequently sighted as a complication discrediting autogenous cranioplasty and questioning its status of being the gold standard. ${ }^{43}$ Ewald et $\mathrm{al}^{44}$ reported on 76 cases of cranioplasty performed with cryopreserved bone flaps and reported a bone flap necrosis rate of $22.8 \%$ in her study. Korhonen et $\mathrm{al}^{43}$ found bone flap resorption a very common phenomenon, occurring at least to some degree in $90 \%$ of the patients, especially prominent in patients younger than 30 years of age. They however opined that partial resorption is most likely a normal physiological phenomenon during the bone revitalization process. Bone flap resorptions have been classified as type I necrosis, showing a thinning of the bone flap and/or a beginning of resorption along the rims of the flap, and a type II bone flap necrosis, characterized by a circumscribed, complete lysis of the bone within the flap, including tabula interna and externa with loss of the bony protection of the brain. ${ }^{45}$ Dünisch et al, ${ }^{45}$ in their retrospective study of 372 patients who received 414 bone flaps, found type II bone flap necrosis in 85 patients (22.8\%) and 91 bone flaps, after a median time of 15 months. Clinical presentations of cases of flap necrosis in these large series of retrospective studies were not recorded.

Various complaints with which the patients presented, as reported in the case reports, were (i) sensation of a floating flap, ${ }^{46}$ (ii) headache, ${ }^{47}$ (iii) clinically appreciable sinking of the scalp flap, ${ }^{48}$ and (iv) breakdown of skull contour. ${ }^{49}$

Of our patients with significant flap resorption, one was asymptomatic and the second had ill-defined headache on exertion, a symptom common among the rest of the patients in the cranioplasty group. None had any feature of sunken flap syndrome. Pediatric age group and fragmented bone flaps have been found to be two important risk factors in development of aseptic resorption of bones after cranioplasty; none of our cranioplasty flaps were fragmented and we had excluded pediatric age group patients from our study, which could be a reason for a very low rate of aseptic resorption seen in our study. ${ }^{28}$

Retrospective study on 108 cases of cranioplasty by Ernst et al, ${ }^{31}$ in which subcutaneous bone flap storage was done, the mean time to cranioplasty was 104.31 days. Severe resorption occurred in 10 cases (9.26\%): 4 were clinically significant ( 2 early and 2 late) and 6 demonstrated type II (severe) necrosis on CT, but did not require revision. Shuntdependent hydrocephalus (OR: 7.97; 95\% CI: 1.57-40.46) and presence of postcranioplasty drain (OR: 9.39; 95\% CI: 1.14-1,000) were found to be significant risk factors for bone resorption. At our center, it is a standard practice to leave a suction drain after cranioplasty, which is removed on the third postoperative day, or when drain is less than 30cc (whichever is later). Though not considered separately as a 
variable, since drains were placed in all the cases, our study obviously did not find drain placement to have any implication on flap resorption. One patient each from the case and control cohorts in our study had hydrocephalus. Both had a good radiological union of the flap.

\section{Conclusion}

Cranioplasty and union of calvarial bones continue to be subjects marred with controversies. Surfacing of claims and counterclaims of superiority of one technique over another is never-ending. We have presented our center's experience over last 10 years combining retrospective and prospective data. Ours is a study with a small sample size, unable to put its weight on any side, but can surely add some more data to help the neurosurgeons in choosing the best for their patients.

\section{Conflict of Interest \\ None declared.}

\section{References}

1 Vahedi K, Hofmeijer J, Juettler E, et al; DECIMAL, DESTINY, and HAMLET investigators. Early decompressive surgery in malignant infarction of the middle cerebral artery: a pooled analysis of three randomised controlled trials. Lancet Neurol 2007;6(3):215-222

2 Aarabi B, Hesdorffer DC, Ahn ES, Aresco C, Scalea TM, Eisenberg HM. Outcome following decompressive craniectomy for malignant swelling due to severe head injury. J Neurosurg 2006;104(4):469-479

3 Perin A, Nascimben E, Longatti P. Decompressive craniectomy in a case of intractable intracranial hypertension due to pneumococcal meningitis. Acta Neurochir (Wien) 2008;150(8):837-842, discussion 842

4 Zuurbier SM, Coutinho JM, Majoie CBLM. Coert BA, van den Munckhof P, Stam J. Decompressive hemicraniectomy in severe cerebral venous thrombosis: a prospective case series. J Neurol 2012;259(6):1099-1105

5 Schneider GH, Bardt T, Lanksch WR, Unterberg A. Decompressive craniectomy following traumatic brain injury: ICP, CPP and neurological outcome. Acta Neurochir Suppl (Wien) 2002;81:77-79

6 Olivecrona M, Rodling-Wahlström M, Naredi S, Koskinen LO. Effective ICP reduction by decompressive craniectomy in patients with severe traumatic brain injury treated by an ICPtargeted therapy. J Neurotrauma 2007;24(6):927-935

7 Cooper DJ, Rosenfeld JV, Murray L, et al; DECRA Trial Investigators; Australian and New Zealand Intensive Care Society Clinical Trials Group. Decompressive craniectomy in diffuse traumatic brain injury. $\mathrm{N}$ Engl J Med 2011;364(16):1493-1502

8 Carney N, Totten AM, O'Reilly C, et al. Guidelines for the management of severe traumatic brain injury. Neurosurgery 2017;80(1):6-15

9 Staffa G, Nataloni A, Compagnone C, Servadei F. Custom made cranioplasty prostheses in porous hydroxy-apatite using 3D design techniques: 7 years experience in 25 patients. Acta Neurochir (Wien) 2007;149(2):161-170, discussion 170

10 Staffa G, Barbanera A, Faiola A, et al. Custom made bioceramic implants in complex and large cranial reconstruction: a twoyear follow-up. J Craniomaxillofac Surg 2012;40(3):e65-e70

11 Kim B-J, Hong K-S, Park K-J, Park DH, Chung YG, Kang SH. Customized cranioplasty implants using three-dimensional printers and polymethyl-methacrylate casting. J Korean Neurosurg Soc 2012;52(6):541-546

12 Lethaus B, Bloebaum M, Essers B. ter Laak MP, Steiner T, Kessler P. Patient-specific implants compared with stored bone grafts for patients with interval cranioplasty. J Craniofac Surg 2014;25(1):206-209

13 Rosenthal G, Ng I, Moscovici S, et al. Polyetheretherketone implants for the repair of large cranial defects: a 3-center experience. Neurosurgery 2014;75(5):523-529, discussion 528-529

14 Shah AM, Jung H, Skirboll S. Materials used in cranioplasty: a history and analysis. Neurosurg Focus 2014;36(4):E19

15 Flannery T, McConnell RS. Cranioplasty: why throw the bone flap out. ? Br J Neurosurg 2001;15(6):518-520

16 Odom GL, Woodhall B, Wrenn FR Jr. The use of refrigerated autogenous bone flaps for cranioplasty. J Neurosurg 1952;9(6):606-610

17 Zhang J, Peng F, Liu Z, et al. Cranioplasty with autogenous bone flaps cryopreserved in povidone iodine: a long-term follow-up study. J Neurosurg 2017;127(6):1449-1456

18 Yadla S, Campbell PG, Chitale R, Maltenfort MG, Jabbour P, Sharan AD. Effect of early surgery, material, and method of flap preservation on cranioplasty infections: a systematic review. Neurosurgery 2011;68(4):1124-1129, discussion 1130

19 Rossini Z, Nicolosi F, Kolias AG, Hutchinson PJ, De Sanctis P, Servadei F. The history of decompressive craniectomy in traumatic brain injury. Front Neurol 2019;10:45810.3389/ fneur.2019.00458

20 Feroze AH, Walmsley GG, Choudhri O, Lorenz HP, Grant GA, Edwards MS. Evolution of cranioplasty techniques in neurosurgery: historical review, pediatric considerations, and current trends. J Neurosurg 2015;123(4):1098-1107

21 Andrabi SM, Sarmast AH, Kirmani AR, Bhat AR. Cranioplasty: indications, procedures, and outcome - an institutional experience. Surg Neurol Int 2017;8:91

22 Paredes I, Castaño-León AM, Munarriz PM, et al. Cranioplasty after decompressive craniectomy. A prospective series analyzing complications and clinical improvement. Neurocirugia (Astur) 2015;26(3):115-125

23 Honeybul S, Morrison DA, Ho KM, Lind CRP, Geelhoed E. A randomized controlled trial comparing autologous cranioplasty with custom-made titanium cranioplasty. J Neurosurg 2017;126(1):81-90

24 Kumar P, Kumar A, Jaiswal G, Gupta TK. Bone flap preservation in abdominal wall after decompressive craniectomy in head injury: a single institute experience. Romanian NeurosurgXXXII 2018;3:491-495

25 Krishnan P, Bhattacharyya AK, Sil K, De R. Bone flap preservation after decompressive craniectomy-experience with 55 cases. Neurol India 2006;54(3):291-292

26 Morina A, Kelmendi F, Morina Q et al. Cranioplasty with subcutaneously preserved autologous bone grafts in abdominal wall - experience with 75 cases in a post-war country Kosovo. Surg Neurol Int 2011;2:7210.4103/2152-7806.81735

27 Shoakazemi A, Flannery T, McConnell RS. Long-term outcome of subcutaneously preserved autologous cranioplasty. Neurosurgery 2009;65(3):505-510, discussion 510

28 Iwama T, Yamada J, Imai S, Shinoda J, Funakoshi T, Sakai N. The use of frozen autogenous bone flaps in delayed cranioplasty revisited. Neurosurgery 2003;52(3):591-596, discussion 595-596

29 Fan MC, Wang QL, Sun P, et al. Cryopreservation of autologous cranial bone flaps for cranioplasty: a large sample retrospective study. World Neurosurg 2018;109:e853-e859

30 Cheng CH, Lee HC, Chen CC, Cho DY, Lin HL. Cryopreservation versus subcutaneous preservation of autologous bone flaps for cranioplasty: comparison of the surgical site infection and bone resorption rates. Clin Neurol Neurosurg 2014;124:85-89 
31 Ernst G, Qeadan F, Carlson AP. Subcutaneous bone flap storage after emergency craniectomy: cost-effectiveness and rate of resorption. J Neurosurg 2018;129(6):1604-1610

32 Piitulainen JM, Kauko T, Aitasalo KM, Vuorinen V, Vallittu PK, Posti JP. Outcomes of cranioplasty with synthetic materials and autologous bone grafts. World Neurosurg 2015;83(5):708-714

33 Adaaquah D, Gates M, Gompel JJ. Rate of craniotomy fusion after free bone flap. World Neurosurg 2018;118:e283-e287

34 Vagnerova K, Koerner IP, Hurn PD. Gender and the injured brain. Anesth Analg 2008;107(1):201-214

35 Jeon JP, Heo Y, Kang S-H, Yang JS, Choi HJ, Cho Y-J. Retrospective chronologic computed tomography analysis of bone flap fusion and resorption after craniotomy and autologous cryopreserved cranioplasty. World Neurosurg 2019;129:e900-e906

36 Rish BL, Dillon JD, Meirowsky AM, et al. Cranioplasty: a review of 1030 cases of penetrating head injury. Neurosurgery 1979;4(5):381-385

37 Bjornson A, Tajsic T, Kolias AG, et al. A case series of early and late cranioplasty - comparison of surgical outcomes. Acta Neurochir (Wien) 2019;161(3):467-472

38 Aydin S, Kucukyuruk B, Abuzayed B, Aydin S, Sanus GZ. Cranioplasty: review of materials and techniques. J Neurosci Rural Pract 2011;2(2):162-167

39 Carvi Y Nievas MN, Höllerhage HG. Early combined cranioplasty and programmable shunt in patients with skull bone defects and CSF-circulation disorders. Neurol Res 2006;28(2):139-144

40 Beauchamp KM, Kashuk J, Moore EE, et al. Cranioplasty after postinjury decompressive craniectomy: is timing of the essence? J Trauma 2010;69(2):270-274

41 Singh S, Singh R, Jain K, Walia B. Cranioplasty following decompressive craniectomy - analysis of complication rates and neurological outcomes: a single center study. Surg Neurol Int 2019;10:14210.25259/SNI_29_2019

42 Lerch K-D. Reliability of cranial flap fixation techniques: comparative experimental evaluation of suturing, titanium miniplates, and a new rivet-like titanium clamp (CranioFix): technical note. Neurosurgery 1999;44(4):902-905

43 Korhonen TK, Salokorpi N, Niinimäki J, Serlo W, Lehenkari P, Tetri S. Quantitative and qualitative analysis of bone flap resorption in patients undergoing cranioplasty after decompressive craniectomy. J Neurosurg 2018;130(1):312-321

44 Ewald C, Duenisch P, Walter J, et al. Bone flap necrosis after decompressive hemicraniectomy for malignant middle cerebral artery infarction. Neurocrit Care 2014;20(1):91-97

45 Dünisch P, Walter J, Sakr Y, Kalff R, Waschke A, Ewald C. Risk factors of aseptic bone resorption: a study after autologous bone flap reinsertion due to decompressive craniotomy. J Neurosurg 2013;118(5):1141-1147

46 Ying K, Hsu S-K, Huang C-T. Bone flap malunion and resorption after cranioplasty with bioabsorbable implants in an adult drug abuser. Resuscitation \& Intensive Care Med 2016;1:168-172

47 Yin J, Jiang Y. Completely resorption of autologous skull flap after orthotopic transplantation: a case report. Int J Clin Exp Med 2014;7(4):1169-1171

48 de França SA, Nepomuceno TB, Paiva WS, Andrade AF, Teixeira MJ, Tavares WM. Cranial autologous bone flap resorption after a cranioplasty: a case report. Surg Neurol Int 2018;9:61

49 Son S, Park CW, Kim EY, Kim JM, Yoo CJ. Bone resorption of autologous cranioplasty following decompressive craniectomy in children. J Kor Neurotraumatol Soc 2009;5:118-12 